\title{
Functional and biochemical characterization of the 205 proteasome in a yeast temperature-sensitive mutant, rpt6-I
}

\author{
Aktar Uzzaman Chouduri ${ }^{1}$, Toshinobu Tokumoto ${ }^{1}$, Hideo Dohra ${ }^{2}$, \\ Takashi Ushimaru ${ }^{1}$ and Shinpei Yamada*1
}

Address: ${ }^{1}$ Department of Biology, Faculty of Science, National University Corporation, Shizuoka University, 836 Oya, Suruga-ku, Shizuoka $422-$ 8529, Japan and 2 Institute for Genetic Research and Biotechnology, National University Corporation, Shizuoka University, 836 Oya, Suruga-ku, Shizuoka 422-8529, Japan

Email: Aktar Uzzaman Chouduri - auchow5@yahoo.com; Toshinobu Tokumoto - sbttoku@ipc.shizuoka.ac.jp;

Hideo Dohra - gihdour@ipc.shizuoka.ac.jp; Takashi Ushimaru - sbtushi@ipc.shizuoka.ac.jp; Shinpei Yamada* - sbsyama@ipc.shizuoka.ac.jp

* Corresponding author

Published: 21 July 2008

BMC Biochemistry 2008, 9:20 doi:10.1|86/|47|-209|-9-20
Received: 7 February 2008

Accepted: 21 July 2008

This article is available from: http://www.biomedcentral.com/I47I-209I/9/20

(c) 2008 Chouduri et al; licensee BioMed Central Ltd.

This is an Open Access article distributed under the terms of the Creative Commons Attribution License (http://creativecommons.org/licenses/by/2.0), which permits unrestricted use, distribution, and reproduction in any medium, provided the original work is properly cited.

\begin{abstract}
Background: Rpt6-I is a thermosensitive yeast mutant with a deletion of a gene encoding a regulatory subunit of the $26 \mathrm{~S}$ proteasome, $R P T 6$, which is able to grow at $25^{\circ} \mathrm{C}$ but not at $37^{\circ} \mathrm{C}$. In this study, peptidase activities, activation profiles, and the subunit composition of the $20 \mathrm{~S}$ proteasome purified from the rpt6-I mutant was characterized.
\end{abstract}

Results: The 20S proteasome purified from rpt6-I exhibited low levels of peptidase activities in the absence of activators, but nearly same activated activities in the presence of activators, suggesting a gating defect in the proteasome channel. Detailed analyses of the composition of the $20 S$ proteasome through separation of all subunits by two-dimensional gel electrophoresis followed by identification of each subunit using MALDI-TOF-MS revealed that two subunits, $\alpha I$ and $\alpha 7$, differed from those of wild-type cells in both electrophoretic mobility and $p /$ values. The changes in these two $\alpha$-subunits were apparent at the permissive temperature, but disappeared during stress response at the restrictive temperature. Interestingly, upon disappearance of these changes, the levels of peptidase activity of the $20 \mathrm{~S}$ proteasome in the rpt6-I mutant were restored as the wild-type. These results suggest that two different forms of the $\alpha$-subunits, $\alpha \mid$ and $\alpha 7$, block the proteasome channel in the rpt6-I mutant.

Conclusion: Two $\alpha$-subunits $(\alpha \mid$ and $\alpha 7)$ of the 20S proteasome in the rpt6-I mutant differed from their wild-type counterparts and peptidase activities were found to be lower in the mutant than in the wild-type strain.

\section{Background}

The 26S proteasome is an essential enzyme found in all eukaryotic cells $[1,2]$ consisting of a cylinder-shaped multimeric complex, the $20 \mathrm{~S}$ proteasome core particle, capped at each end by another multimeric complex, the $19 S$ regulatory unit. The ATPase ring of the regulatory unit comprising six ATPase subunits (Rpt1-Rpt6) associates directly with the $20 \mathrm{~S}$ proteasome and is thought to play multiple roles within the complex [3]. The 20S proteasome degrades unfolded substrate proteins in an ATP- and ubiquitin-independent manner [4]. It has been proposed that both unfolding and translocation of substrates are 
mediated by the six ATPases [5,6]. Crystallographic structural analysis shows that the ends of the 20S proteasome are in a closed state [7]. It has also been postulated that the ATPases can open the proteasome channel leading to the proteolytic chamber within the 20S proteasome [5]. The 20S proteasome functions as the catalytic center of the $26 \mathrm{~S}$ proteasome that can cleave peptides on the carboxyl side of hydrophobic, basic, and acidic amino acids in vitro that have been designated as chymotrypsin-like, trypsinlike, and PGPH activities, respectively [8].

The entrance to the 20S proteasome cavity is closed [7]. The $\mathrm{N}$-terminal tails of the different $\alpha$-subunits adopt different conformations in the closed state and point inwards to block access through the proteasome channel [9]. Due to the narrow entrance of the 20S proteasome, access is restricted. It is thought that channel gating is regulated by the ATPase subunits in the $19 \mathrm{~S}$ regulatory unit $[10,11]$. Little is known about this process in eukaryotic proteasomes. The closed channel of the eukaryotic $20 \mathrm{~S}$ proteasome can be stimulated by a variety of means; one of which is mild chemical treatment, such as the exposure to low concentrations of SDS [12]. The stimulation may reflect opening of the proteasome channel that allows greater access of protein substrates to the proteolytic chamber. The $\mathrm{N}$-terminal segments of various $\alpha$-subunits that seal the central channel are generally rearranged to yield the activated form [7].

The rpt6-1 Saccharomyces cerevisiae mutant is temperaturesensitive for growth, being able to grow at $25^{\circ} \mathrm{C}$ but not at $37^{\circ} \mathrm{C}$ with cell division arrested in G2/Metaphase [13]. Normally, traffic through the ubiquitin-proteasome pathway is greatly increased in cells at an elevated temperature due to the abundance of misfolded or partially denatured protein substrates that must be removed. The defective proteasome in the rpt6-1 mutant is unable to process the increased protein traffic properly and cells eventually die due to the deleterious effects of accumulated misfolded proteins [14].

The rpt6-1 deletion mutant has been used previously [15$17]$. In this study, we isolated the $20 \mathrm{~S}$ proteasome from the rpt6-1 mutant and compared its peptidase activities to those of the wild-type strain. Surprisingly, distinct changes in peptidase activities and in subunit composition were observed in the $20 \mathrm{~S}$ proteasome. A detailed comparative analysis using two-dimensional gel electrophoresis and mass spectrometry was then undertaken to investigate the molecular mechanism(s) responsible for the observed changes.

\section{Methods \\ Chemicals}

The peptide substrates, Suc-LLVY-MCA, Boc-LRR-MCA, and Z-LLE-MCA, were purchased from Peptide Institute (Osaka, Japan). The IPG DryStrip (pH 3-10 NL; non-linear) was purchased from Amersham Bioscience (Piscataway, NJ, USA). Acetonitrile (chromatogram-grade), acetone, iodoacetamide, urea, and TFA were from Wako Pure Chemical Industries (Osaka, Japan). Modified trypsin (sequencing grade) was from Promega (Tokyo, Japan). The CHCA ( $\alpha$-cyano-4-hydroxy-cinnamic acid) was obtained from Bruker Daltonics (Billerica, MA, USA). Acrylamide, bis-acrylamide, glycine, Tris, SDS, and DTT were from Nakalai Tesque (Kyoto, Japan). Other chemicals were domestic products (analytical grade).

\section{Yeast strains and growth}

The following strains of yeast were used: the wild-type strain W303-1A (MAT leu2 his3 trp1 ura3 ade2 can1) and

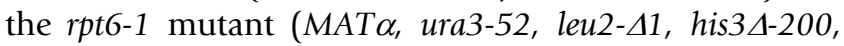
cim3-1). The rpt6-1 strain was a gift from Dr. Akio Toh-e (Department of Biological Sciences, Tokyo University). Yeast cells were grown in YPAD medium $(1 \%$ yeast extract, $2 \%$ meat peptone, $0.01 \%$ adenine, and $2 \% \mathrm{D}(+)$ glucose) at $25^{\circ} \mathrm{C}$ and $37^{\circ} \mathrm{C}$ to an absorbance of 2.0 at 600 $\mathrm{nm}\left(\mathrm{OD}_{600 \mathrm{~nm}}\right)$.

\section{Plasmid construction}

The expression plasmid p423GPD-RPT6 was constructed by insertion of the RPTG ORF amplified by PCR using primers RPT6F1，5'-GTGGATCCCCCGGGCTGCAGATGACAGCTGCTGTAACATCC-3' and RPT6R1, 5'GTATCGATAAGCTTGATATCTCACTTGAACAGCTTGGCG-3' (the bold bases are complementary to plasmid p423GPD), into plasmid p423GPD [18] digested with EcoRI. Plasmid construction was performed by homologous recombination in rpt6-1 cells according to standard methods.

\section{Purification of the 20 S proteasome}

The 20S proteasome was purified as described in [7] with minor modifications. Yeast cells were washed twice with ice-cold water and suspended in an equal volume of lysis buffer (40 mM Tris-HCl, pH 7.5, 2 mM EDTA, 1 mM DTT, and $20 \%$ glycerol). The cell suspension was subjected to five cycles of vigorous vortexing with glass beads $(0.2 \mathrm{~mm}$ diameter) for $5 \mathrm{~min}$. and chilling on ice for $1 \mathrm{~min}$ between cycles. After filtration, the cell lysate was centrifuged for 50 $\min$ at $96,000 \times \mathrm{g}$. The supernatant was immediately applied to a Q-sepharose column $(2.5 \times 8 \mathrm{~cm})$ previously equilibrated with $200 \mathrm{mM} \mathrm{NaCl}$ in buffer A $(20 \mathrm{mM}$ Tris$\mathrm{HCl}, \mathrm{pH} 7.5,1 \mathrm{mM}$ EDTA, $0.5 \%$ DTT, and 10\% glycerol). The column was washed with the same buffer and eluted with a gradient of $200-600 \mathrm{mM} \mathrm{NaCl}$ in buffer A. SucLLVY-MCA hydrolyzing activity was assayed in all eluted 
fractions in the presence and absence of SDS. The proteasome eluted at $\sim 400 \mathrm{mM} \mathrm{NaCl}$. Active fractions were pooled and diluted three-fold with ice-cold water. The diluted sample was applied to a hydroxyapatite column $(1.6 \times 7.5 \mathrm{~cm})$ previously equilibrated with buffer B (60 mM K-phosphate, pH 7.5, and 10\% glycerol). The column was washed with the same buffer and eluted with a gradient of 60-300 mM K-phosphate containing 10\% glycerol. The proteasome eluted at $\sim 200 \mathrm{mM}$ K-phosphate. Active fractions were combined and concentrated by ultrafiltration using an AMICON YM30 membrane (Millipore Corporation, USA). The concentrated sample was applied to a Superose- 6 column $(1.6 \times 50 \mathrm{~cm})$ and eluted with buffer A excluding DTT. The active fractions were combined, concentrated, and stored at $-20^{\circ} \mathrm{C}$ prior to use. All preparative steps were carried out at $4^{\circ} \mathrm{C}$. The concentration of the purified 20S proteasome was measured by the Bradford method [19] using BSA as a standard and purity was checked by nondenaturing-PAGE and SDS-PAGE.

\section{Assays of proteasome activity}

The activity of the $20 \mathrm{~S}$ proteasome to hydrolyze peptidyl substrates was measured at $37^{\circ} \mathrm{C}$ in a $200 \mu \mathrm{l}$ reaction mixture containing $50 \mathrm{mM}$ Tris- $\mathrm{HCl}, \mathrm{pH} 7.6$ and $8.5,1 \mu \mathrm{g} / \mathrm{ml}$ $20 \mathrm{~S}$ proteasome, $10 \mu \mathrm{M}$ peptidyl substrate, various concentrations of SDS and linolenic acid, respectively for $1 \mathrm{~h}$. The reaction was started by adding peptidyl substrate solution to the 20S-containing reaction mixture and was stopped by addition of $100 \mu \mathrm{l}$ of 5\% SDS. The reaction mixture was then diluted to $2.0 \mathrm{ml}$ with $100 \mathrm{mM}$ reaction buffer. Fluorescence readings of released 7-amido-4methyl-coumarin (AMC) were measured at an excitation wavelength of $380 \mathrm{~nm}$ and an emission wavelength of $460 \mathrm{~nm}$ in a fluorescence spectrophotometer (F-3000, Hitachi, Tokyo). Activity was calculated as nmol of peptidyl substrate hydrolyzed per mg protein (20S proteasome) per min [20].

\section{Electrophoresis}

SDS-PAGE was performed as described by Laemmli [21] using a $12 \%$ resolving gel and a $4 \%$ stacking gel. Silver staining was carried out by the 2D-Silver stain-II kit (Daiichi pure chemicals Co. Ltd., Tokyo) following the manufacturer's instructions. Nondenaturing-PAGE was performed similarly using a continuous $4 \%$ polyacrylamide gel without SDS in reagents and running buffer.

\section{Western blot analysis}

Purified protein was subjected to SDS-PAGE in a $12 \%$ polyacrylamide gel and electrophoretically transferred to a PVDF membrane. Nonspecific binding was blocked with 5\% nonfat dried skim milk (Wako) in Tris-buffered saline, $0.1 \%$ Tween-20 (TBS-T) overnight at $4{ }^{\circ} \mathrm{C}$. Blots were washed with TBS-T for $15 \mathrm{~min}$., incubated with primary antibody in TBS-T for $1 \mathrm{~h}$ at room temperature. The primary anti- $\alpha 7$ monoclonal antibody (clone MCP72) was purchased from BIOMOL International, LP, USA and anti-Xenopus $\alpha 1$ polyclonal antibody was prepared as described in Wakata et al. [22]. After washing with TBS-T as above, the blots were incubated with horseradish peroxidase conjugated secondary antibody, mouse anti-rabbit IgG for the $\alpha 7$, and guinea pig anti-Xenopus IgG for the $\alpha 1$ subunit for $1 \mathrm{~h}$ at room temperature. The blots were washed as above and bound antibody was visualized using an ECL western blotting detection system [23].

\section{Two-dimensional gel electrophoresis}

The purified 20S proteasome was subjected to two-dimensional polyacrylamide gel electrophoresis as described in Horiguchi et al. [24]. The purified 20S proteasome (70 $\mu \mathrm{g})$ from each strain was mixed with $200 \mu$ of IEF sample buffer containing $9 \mathrm{M}$ urea, $2 \%$ nonidet $\mathrm{P}-40,5 \%$ mercaptoethanol, and $1.5 \%$ pharmalyte (pH 3-10) and applied to IPG DryStrip (pH 3-10 NL; $130 \times 3 \times 0.5 \mathrm{~mm})$. After rehydration for $>20 \mathrm{~h}$ at room temperature, IEF was conducted in gradient mode for $10 \mathrm{~min}$. at $0-500 \mathrm{~V}$ (first phase), $5 \mathrm{~h}$ at $500 \mathrm{~V}$ (second phase), $5 \mathrm{~h}$ at $500-3500 \mathrm{~V}$ (third phase) followed by $5 \mathrm{~h}$ at $3500 \mathrm{~V}$ (fourth phase) at $15^{\circ} \mathrm{C}$ on a Multiphor II flat bed electrophoresis unit (Pharmacia Biotech). After IEF separation, the gel strips were equilibrated for $10 \mathrm{~min}$ in equilibration buffer A containing $50 \mathrm{mM}$ Tris- $\mathrm{HCl}$, pH 6.8, $6 \mathrm{M}$ urea, 30\% glycerol, $1 \%$ SDS, and $0.25 \%$ DTT followed by equilibration buffer B for 10 min where DTT was replaced by $4.5 \%$ iodoacetamide. The second dimension of separation was carried out in SDS polyacrylamide vertical slab gels with $12 \%$ separating and $4 \%$ stacking gels and a constant current of $30 \mathrm{~mA} / \mathrm{gel}$. After electrophoresis, proteins were visualized by Coomassie Brilliant Blue R-250 staining and all visible spots were selected for in-gel digestion.

\section{In-gel digestion}

The excised protein spots were destained by repeated washing with a $400 \mu \mathrm{l}$ solution containing $50 \%$ acetonitrile and $50 \mathrm{mM} \mathrm{NH}_{4} \mathrm{HCO}_{3}$. The gel pieces were incubated with $100 \mu \mathrm{l}$ of acetonitrile for $10 \mathrm{~min}$ and then dried under vacuum. The dried gel was incubated at $56^{\circ} \mathrm{C}$ with a $20 \mu \mathrm{l}$ solution of $10 \mathrm{mM}$ DTT and $50 \mathrm{mM}$ $\mathrm{NH}_{4} \mathrm{HCO}_{3}$ for $45 \mathrm{~min}$. and then dried again under vacuum. Digestions were performed overnight at $37^{\circ} \mathrm{C}$ with trypsin. The digested peptides were eluted by sonicating the gel pieces in a $3 \mu$ solution of $50 \%$ ACN $/ 1 \%$ TFA for $15 \mathrm{~min}$ in a mini sonicator. The peptide mixture was then transferred to a new tube, resuspended in $10 \mu \mathrm{l}$ of $0.1 \%$ TFA, and used for sequence analysis.

\section{Peptide mass fingerprinting}

ZipTip $_{\mu \text {-C18 }}$ (Millipore) pipette tips were pre-wetted with a $10 \mu \mathrm{l}$ solution of $50 \%$ acetonitrile $/ 0.1 \%$ trifluoroacetic acid. Adsorption of peptides was performed by repeated 
pipetting of the peptide mixture solution from each gel spot. The resulting bound peptides were desalted with 10 $\mu \mathrm{l}$ of $0.1 \%$ TFA and spotted on a MALDI target plate that was double layered with $\alpha$-cyano-4-hydroxycinnamic acid dissolved in acetone. The spots were air-dried and molecular mass information was obtained using a MALDI-TOFMS Autoflex (Bruker Daltonics, Billerica, MA) in the positive ion mode. All MALDI-TOF-MS spectra were externally calibrated using a molecular weight standard mixture (Bruker Daltonics). The peptide MS fingerprint was subjected to a search of the NCBInr database using MASCOT software (Matrix Science, London, UK). The search was performed using the following settings: the Saccharomyces cerevisiae (Baker's yeast) database, trypsin digest, and variable modification-carbamidomethylation of cysteine. Initially, mass tolerances were set to $\pm 0.1 \mathrm{Da}$, and a single missed tryptic cleavage site was allowed. Mass tolerances were relaxed to \pm 0.2 Da for PMFs which did not yield significant matches in the first search while all other parameters remained constant [25].

\section{Alkaline phosphatase treatment}

The active Q-sepharose fraction $(10 \mu \mathrm{g})$ was treated with alkaline phosphatase from calf-intestine $(100 \mathrm{U}$, Boehringer Mannheim, Germany) in $50 \mathrm{mM}$ Glycine- $\mathrm{NaOH}$, $\mathrm{pH} 10$ [26] or Tris-HCl, $\mathrm{pH} 7.6$ [27] in the absence and presence of various concentrations of SDS at $37^{\circ} \mathrm{C}$ for $1 \mathrm{~h}$. The alkaline phosphatase-treated $20 \mathrm{~S}$ proteasome was then subjected to immunoblotting analysis using an anti$\alpha 7$ monoclonal antibody.

\section{Data presentation}

Peptidase activity values are presented as means and standard deviations for three independent sets of data.

\section{Results and Discussion}

\section{Assay of 20S proteasome activity and activation profile}

The comparative study of the $20 \mathrm{~S}$ proteasome purified from the rpt6-1 mutant to that of the wild-type strain was carried out using enzymatic and proteomic approaches. In yeast, the 20S proteasome is auto-inhibited by the N-terminal segments of $\alpha$-subunits in the center of the heptameric $\alpha$-ring. The $20 \mathrm{~S}$ proteasome is usually purified in a latent state having low levels of peptidase activities [28] that can be subsequently activated by a mild chaotropic agent, such as SDS or linolenic acid [29]. These agents selectively denature the $\mathrm{N}$-terminal region and open the $\alpha$-channel of the 20 S proteasome cavity $[30,31]$. By use of an enzymatic approach, peptidase activities of the $20 \mathrm{~S}$ proteasome purified from the rpt6-1 mutant $\left(20 \mathrm{~S}_{\mathrm{r}}\right.$ proteasome) and activation profiles were compared to those of the wild-type strain towards three peptidyl substrates; SucLLVY-MCA for chymotrypsin-like activity (hereafter termed LLVY-activity), Z-LLE-MCA for PGPH activity (LLE-activity), and Boc-LRR-MCA for trypsin-like activity
(LRR-activity). Relative to the 20S proteasome purified from the wild-type strain ( $20 \mathrm{~S}_{\mathrm{w}}$ proteasome), $20 \mathrm{~S}_{\mathrm{r}}$ proteasome exhibited weak peptidase activities in the absence of SDS (Fig. 1). Optimal activities were found at $0.01 \%$ SDS in both yeast strains as reported by others $[8,32]$ and that seemed to reflect a convergence (Figs. $1 \mathrm{~A}$ and $1 \mathrm{~B}$ ). The SDS appeared to inactivate LRR-activity as previously found by Thomas et al. (Fig. 1C) [33]. Trypsin-like activity and its SDS-mediated profile in the $20 \mathrm{~S}_{\mathrm{r}}$ proteasome was evaluated using the peptidyl substrate Boc-LRR-MCA even though this type of peptidase is inactivated by SDS. In the absence of SDS, the $20 S_{\mathrm{r}}$ proteasome hydrolyzed less peptidyl substrate than the $20 \mathrm{~S}_{\mathrm{w}}$ proteasome, but both were almost equally active in its presence. This result suggests that the entrance of the $\alpha$-channel in the $20 S_{r}$ proteasome is too narrow to allow passage of a peptidyl substrate to the catalytic chamber.

The polyunsaturated fatty acid, linolenic acid, is another well-known activator of the 20S proteasome [34] and its effect on hydrolysis of peptidyl substrates was also evaluated (Fig. 2). The obtained results were consistent with those of the SDS-mediated activation profile excluding optimal activity, i.e., the activities of the $20 \mathrm{~S}_{\mathrm{r}}$ proteasome in the absence of linolenic acid were very low, but optimal activities were not found to converge with those of the $20 \mathrm{~S}_{\mathrm{w}}$ proteasome, suggesting that the $20 \mathrm{~S}_{\mathrm{r}}$ proteasome was unable to be fully stimulated by either linolenic acid or the experimental conditions. Our findings are similar to those of Thomas et al. [33] who reported linolenic acidmediated stimulation of LLVY-activity and LLE-activity of the $20 \mathrm{~S}$ proteasome from Ostrich skeletal muscle at $\mathrm{pH}$ 9.0, and inactivation of LRR-activity by the same acid. However, the linolenic acid-mediated optimal activities were found at $\sim 50 \mu \mathrm{g} / \mathrm{ml}$ linolenic acid in both strains under the experimental conditions. This result distinguished the $20 S_{\mathrm{r}}$ proteasome from the $20 \mathrm{~S}_{\mathrm{w}}$ proteasome. Moreover, the same activity assay described above was carried out at $25^{\circ} \mathrm{C}$ under the same conditions in order to evaluate whether the low level of activities of the $20 S_{\mathrm{r}}$ proteasome were altered by assay temperature. No significant changes of activities or activation profiles were detected (data not shown). This result was consistent with the possibility of a gating defect in the $20 \mathrm{~S}_{\mathrm{r}}$ proteasome channel.

\section{Effect of reaction $\mathrm{pH}$ on peptidase activities of the $20 \mathrm{~S}$ proteasome}

In order to obtain clearer evidence for weak activity of the $20 \mathrm{~S}_{\mathrm{r}}$ proteasome, we examined the effect of reaction $\mathrm{pH}$ on the peptide-hydrolyzing activities. No significant changes were found for $20 S_{r}$ proteasome activities over a wide range of $\mathrm{pH}$ values (Fig. 3). These results suggested that subunit composition of the 20S proteasome might be related to the low activities. The LLVY- and LLE-activities of the 20S proteasome in both strains exhibited max- 
A

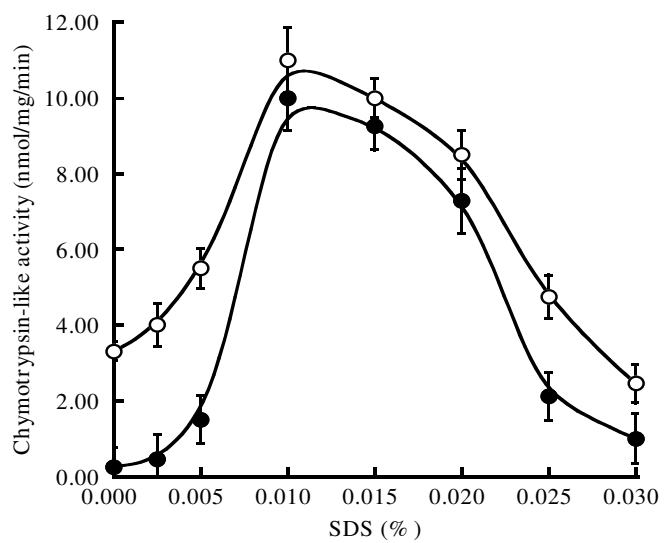

B

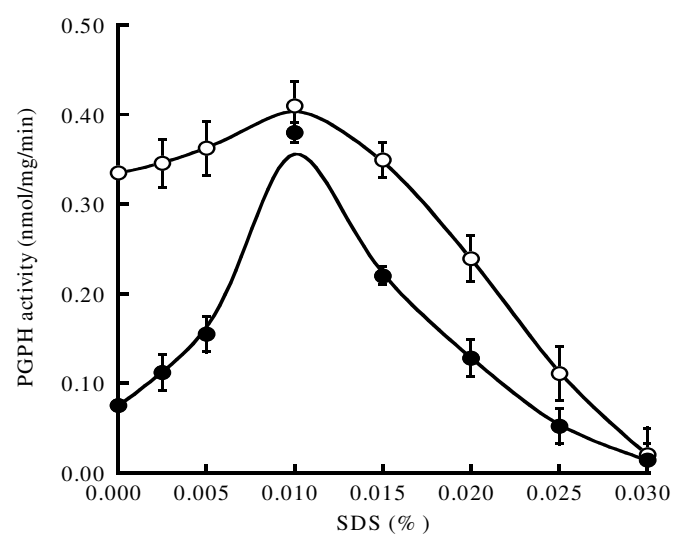

C

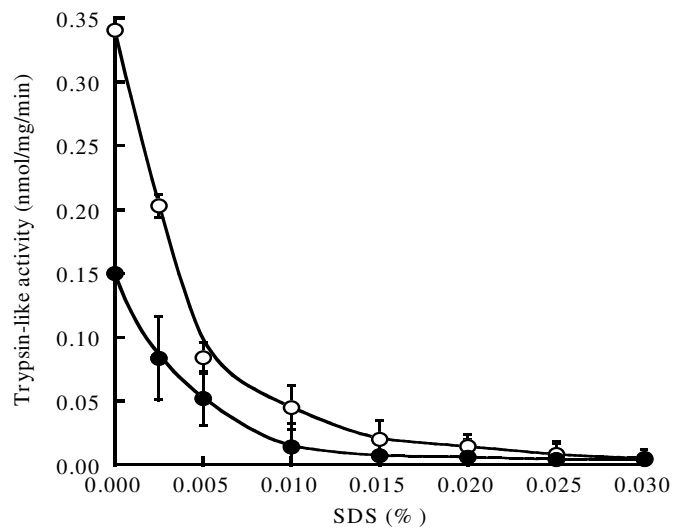

Figure I

SDS-mediated activation profile. Peptide-hydrolyzing activity of the $20 \mathrm{~S}$ proteasome was carried out in a $200 \mu \mathrm{l}$ reaction mixture containing $50 \mathrm{mM}$ Tris- $\mathrm{HCl}, \mathrm{pH} 7.6, \mathrm{I} \mu \mathrm{g} / \mathrm{ml}$ 20S proteasome, and $10 \mu \mathrm{M}$ peptidyl substrates (A: SucLLVY-MCA for chymotrypsin-like activity; B: Z-LLE-MCA for PGPH activity; C: Boc-LRR-MCA for trypsin-like activity) and increasing concentrations of SDS at $37^{\circ} \mathrm{C}$ for I h. The reactions were started and stopped as described in methods. Symbols represent the wild-type strain $(\bigcirc)$ and the rpt6-I mutant $(\bullet)$. Values are means \pm SD of three independent experiments.
A

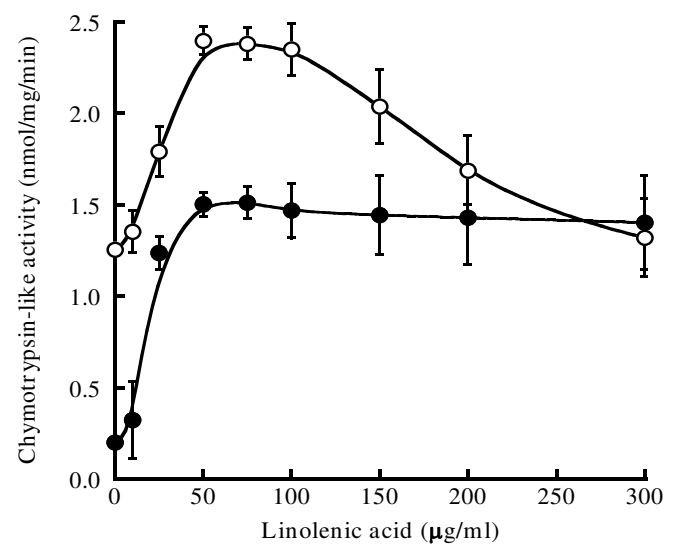

B

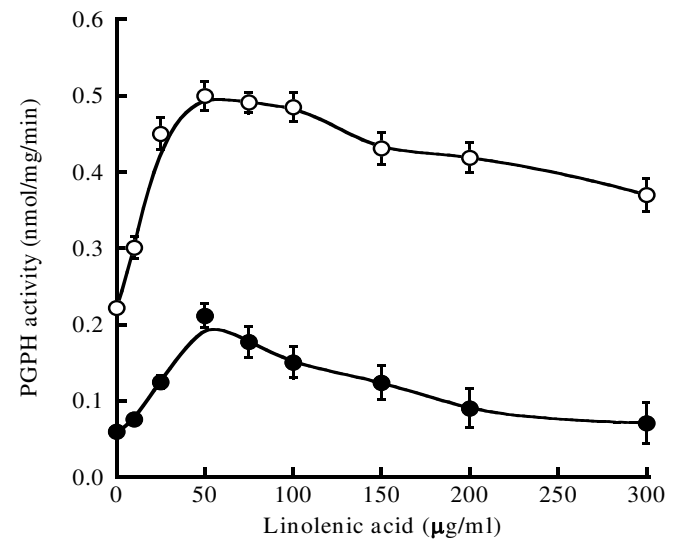

C

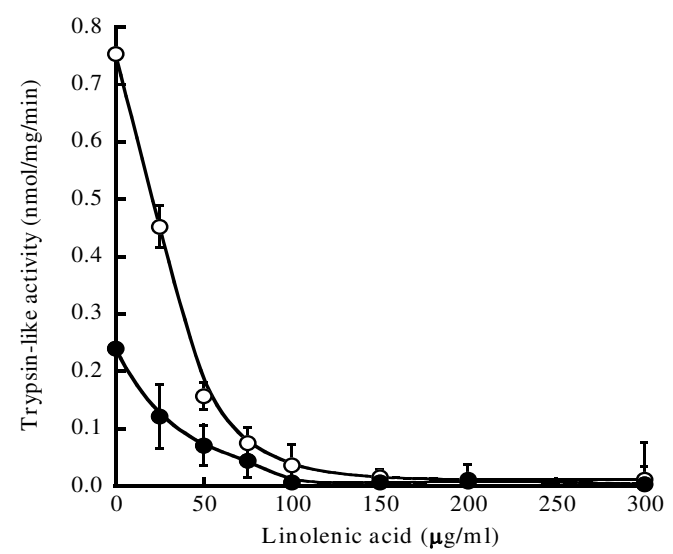

Figure 2

Linolenic acid-mediated activation profile. Assays were carried out in a $200 \mu \mathrm{l}$ reaction mixture containing $50 \mathrm{mM}$ Tris- $\mathrm{HCl}, \mathrm{pH} 8.5, \mathrm{I} \mu \mathrm{g} / \mathrm{ml} 20 \mathrm{~S}$ proteasome, I mM EDTATris, $\mathrm{pH} 8.5,10 \%$ DMSO, and $10 \mu \mathrm{M}$ peptidyl substrates (A: Suc-LLVY-MCA for chymotrypsin-like activity; B: Z-LLEMCA for PGPH activity; C: Boc-LRR-MCA for trypsin-like activity) and increasing concentrations of linolenic acid at $37^{\circ} \mathrm{C}$ for I h. The reactions were started, stopped as described in methods. Symbols represent the wild-type strain $(O)$ and the rpt6-I mutant $(\bullet)$. Values are means \pm SD of three independent experiments. 
A

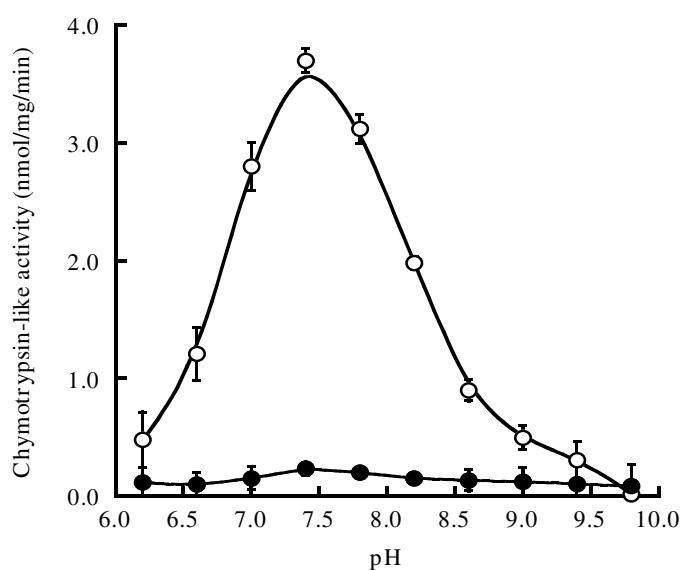

B

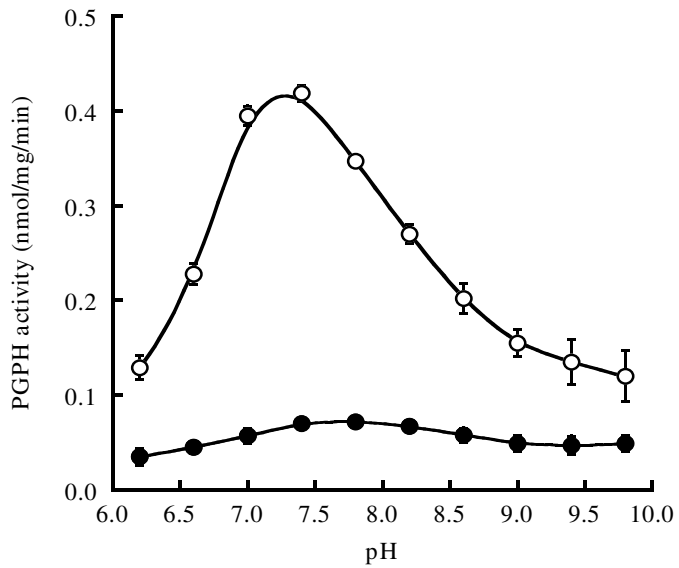

C

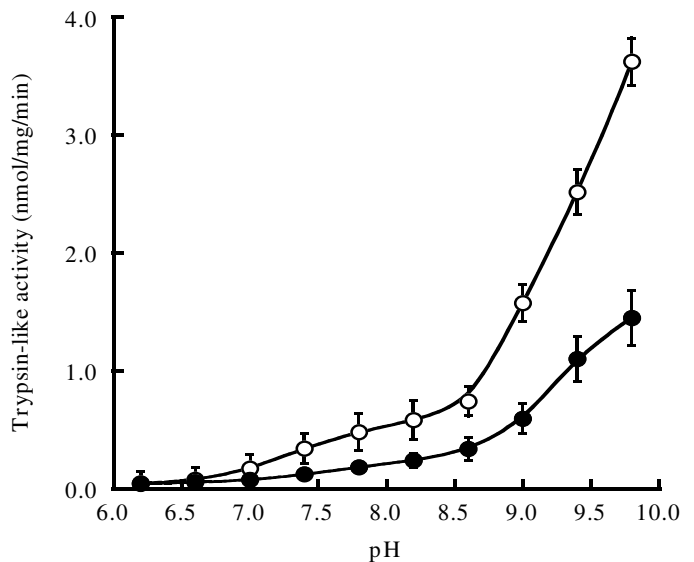

Figure 3

The effect of reaction $\mathrm{pH}$ on peptidase activities. Assays were carried out in a $200 \mu \mathrm{l}$ reaction mixture containing $50 \mathrm{mM}$ HEPES-Tris at $\mathrm{pH} 6.2-9.8, \mathrm{I} \mu \mathrm{g} / \mathrm{ml} 20 \mathrm{~S}$ proteasome, and $10 \mu \mathrm{M}$ of peptidyl substrates (A: Suc-LLVY-MCA for chymotrypsin-like activity; B: Z-LLE-MCA for PGPH activity; C: Boc-LRR-MCA for trypsin-like activity) at $37^{\circ} \mathrm{C}$ for I h. Reactions were started and stopped as described in methods. Symbols represent the wild-type strain $(O)$ and the rpt6-I mutant (0). Values are means \pm SD for three independent experiments.
A

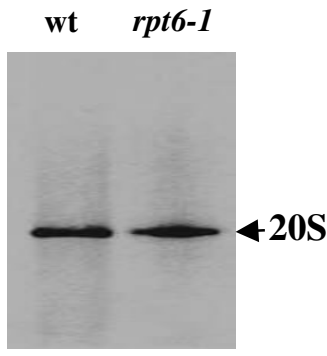

B

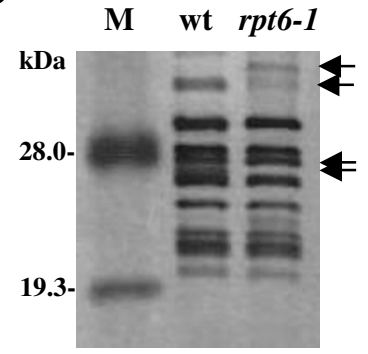

Figure 4

Comparative subunit compositional analysis by onedimensional electrophoresis. (A) Purified 20S proteasomes were subjected to nondenaturing-PAGE in a $4 \%$ continuous polyacrylamide gel and (B) SDS-PAGE in a $12 \%$ polyacrylamide gel. The gels were stained with Coomassie Brilliant Blue R-250 and silver, respectively. The arrows indicate bands differing between strains.

imum values at neutral or weakly alkaline $\mathrm{pH}$, whereas LRR-activities exhibited a maximum at alkaline $\mathrm{pH}$. This observation is similar to the findings of Yanagawa et al. [35] who conducted a comparative study of the effect of reaction $\mathrm{pH}$ on three peptidase activities of the 20S proteasome from rice and spinach. Based on the low level of activities and the activation profiles, we concluded that the 20 S proteasome in $r p t 6-1$ likely had a gating defect.

\section{Subunit compositional analysis of the 205 proteasome by} one-dimensional electrophoresis

Hoffman et al. [36] identified two electrophoretic forms of the $20 \mathrm{~S}$ proteasome from rabbit reticulocytes, a slow form $\left(20 S_{S}\right)$ and a fast form $\left(20 S_{\mathrm{F}}\right)$, and demonstrated the latter to be less active in the hydrolysis of the fluorogenic peptide Suc-LLVY-MCA. In this report, we conducted a comparative analysis of the migration of the intact $20 \mathrm{~S}$ proteasome and its subunits by one-dimensional electrophoresis (Fig. 4) to determine whether the low activity of the $20 S_{\mathrm{r}}$ proteasome was related to its mobility. Our data clearly demonstrated a distinct band in the nondenaturing $4 \%$ polyacrylamide gel without a significant change in mobility (Fig. 4A). But in SDS-PAGE, the banding pattern of the $20 \mathrm{~S}_{\mathrm{r}}$ proteasome differed from that of the $20 \mathrm{~S}_{\mathrm{w}}$ proteasome (Fig. $4 \mathrm{~B}$, arrows), suggesting that changes in the subunits in the $20 \mathrm{~S}_{\mathrm{r}}$ proteasome were responsible for the low peptidase activities.

\section{Proteomic analysis and identification of subunits by mass spectrometry}

To test whether the observed low levels of activities of the $20 S_{\mathrm{r}}$ proteasome were a consequence of the changes in subunit(s), we attempted to analyze each subunit in detail by two-dimensional electrophoresis (2-DE) followed by the sequence analysis of individual subunits extracted 


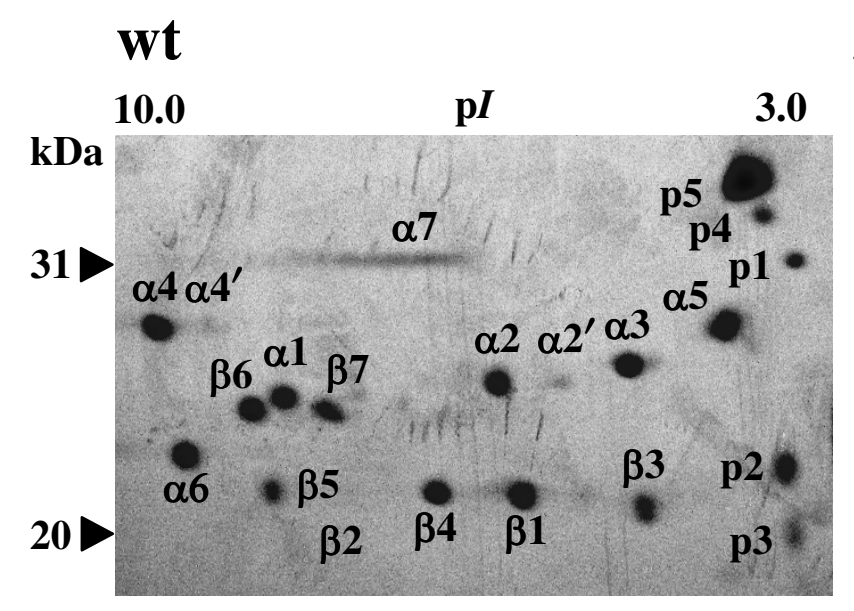

rpt6-1

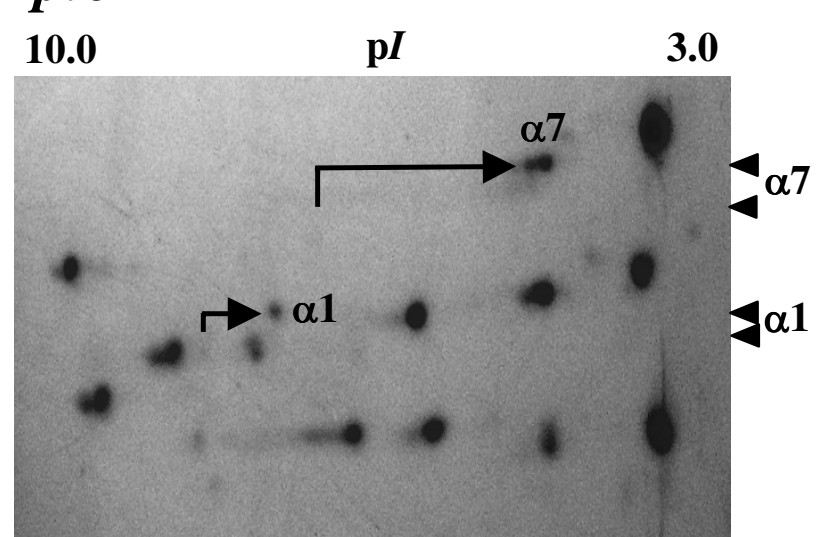

\section{Figure 5}

Two-dimensional electrophoretic pattern of $20 \mathrm{~S}$ proteasome subunits. Purified $20 \mathrm{~S}$ proteasomes (70 $\mu \mathrm{g})$ from each strain were separated using a non-linear IPG strip $(\mathrm{pH} 3-10)$ in the first dimension (left to right) followed by SDS-PAGE in a $12 \%$ polyacrylamide gel in the second dimension (top to bottom). The 2-D gels were stained with Coomassie Brilliant Blue R250. All labeled spots were identified by MALDI-TOF-MS and database searching (Table I). The arrows indicate the shifts of the $\alpha \mathrm{I}$ - and $\alpha 7$-subunits derived from the rpt6-I proteasome towards the acidic side of the gel.

from the 2-D gel. The 2-DE revealed substantial similarities in spotting patterns of subunits of the $20 S_{r}$ proteasome to that of the wild-type with the exception of two spots (Fig. 5). All spots of the 20S proteasome separated by 2-DE were identified by MALDI-TOF-MS (Table 1). Among the fourteen subunits of the 20S proteasome, only the $\beta 2$ subunit could not be identified due to insufficient protein on the gel. Two $\alpha$-subunits $(\alpha 1, \alpha 7)$ in $r p t 6-1$ were found to differ from their wild-type counterparts in spotting pattern in both $\mathrm{pI}$ and molecular weight (Fig. 5). Representative PMF maps of the $\alpha 1$ - and $\alpha 7$-subunits of both strains are shown in figures 6 and 7, respectively. In rpt6-

Table I: A list of 20 S proteasome subunits identified by peptide mass fingerprinting.

\begin{tabular}{|c|c|c|c|c|c|c|}
\hline Spot no. & $\begin{array}{c}\text { Protein } \\
\text { description }\end{array}$ & $\begin{array}{c}\text { Accession } \\
\text { no. (gi) }\end{array}$ & $\begin{array}{c}\text { Theoretical } \\
\text { mass }\left(M_{r}\right)\end{array}$ & $\begin{array}{c}\text { Theoretical } \\
\mathrm{pl}\end{array}$ & $\begin{array}{l}\text { Matched } \\
\text { peptide }\end{array}$ & $\begin{array}{c}\text { Sequence } \\
\text { coverage } \\
(\%)\end{array}$ \\
\hline \multirow[t]{14}{*}{ 20S subunits } & $\alpha l$ & 6321427 & 27983 & 5.89 & 15 & 48 \\
\hline & $\alpha 2$ & 6323547 & $27 \mid 45$ & 5.52 & 16 & 40 \\
\hline & $\alpha 3$ & $31|427|$ & 27003 & 5.71 & 16 & 45 \\
\hline & $\alpha 4$ & 3114272 & 26853 & 6.04 & 17 & 54 \\
\hline & $\alpha 5$ & 3114273 & 26497 & 4.80 & 14 & 43 \\
\hline & $\alpha 6$ & 3114274 & 25457 & 7.08 & 17 & 61 \\
\hline & $\alpha 7$ & |44888 | | & 31386 & 5.04 & 12 & 32 \\
\hline & $\beta I$ & 11513426 & 21709 & 5.36 & 14 & 60 \\
\hline & $\beta 2$ & & & & & \\
\hline & $\beta 3$ & 3114278 & 22459 & 5.05 & 7 & 32 \\
\hline & $\beta 4$ & 6320849 & 22503 & 5.83 & 9 & 41 \\
\hline & $\beta 5$ & 3114280 & 23314 & 5.94 & 8 & 32 \\
\hline & $\beta 6$ & 3114281 & 25457 & 7.08 & 17 & 61 \\
\hline & $\beta 7$ & 3114282 & 25903 & 5.75 & 9 & 41 \\
\hline \multicolumn{7}{|l|}{ Other proteins } \\
\hline pl & SEC65 & 671640 & 31150 & 9.14 & 19 & 37 \\
\hline p2 & YCLOI2w & 10383775 & 25809 & 4.84 & 10 & 24 \\
\hline p3 & YDRI79c & 45269225 & 19464 & 5.07 & 8 & 27 \\
\hline $\mathrm{p} 4$ & (Putative protein of unknown function) & 6321353 & 32092 & 10.02 & 7 & 15 \\
\hline p5 & Secl7 & 6137605 & 32764 & 4.96 & 4 & 17 \\
\hline
\end{tabular}

The top BLAST hit for each spot, its accession number, and sequence coverage to the $S$. cerevisiae proteasomal subunit are shown. The peptide mass fingerprinting was performed using the protein spots from the wild-type strain as shown in Figure 5 . The differentially spotted proteins were identified in both strains. 

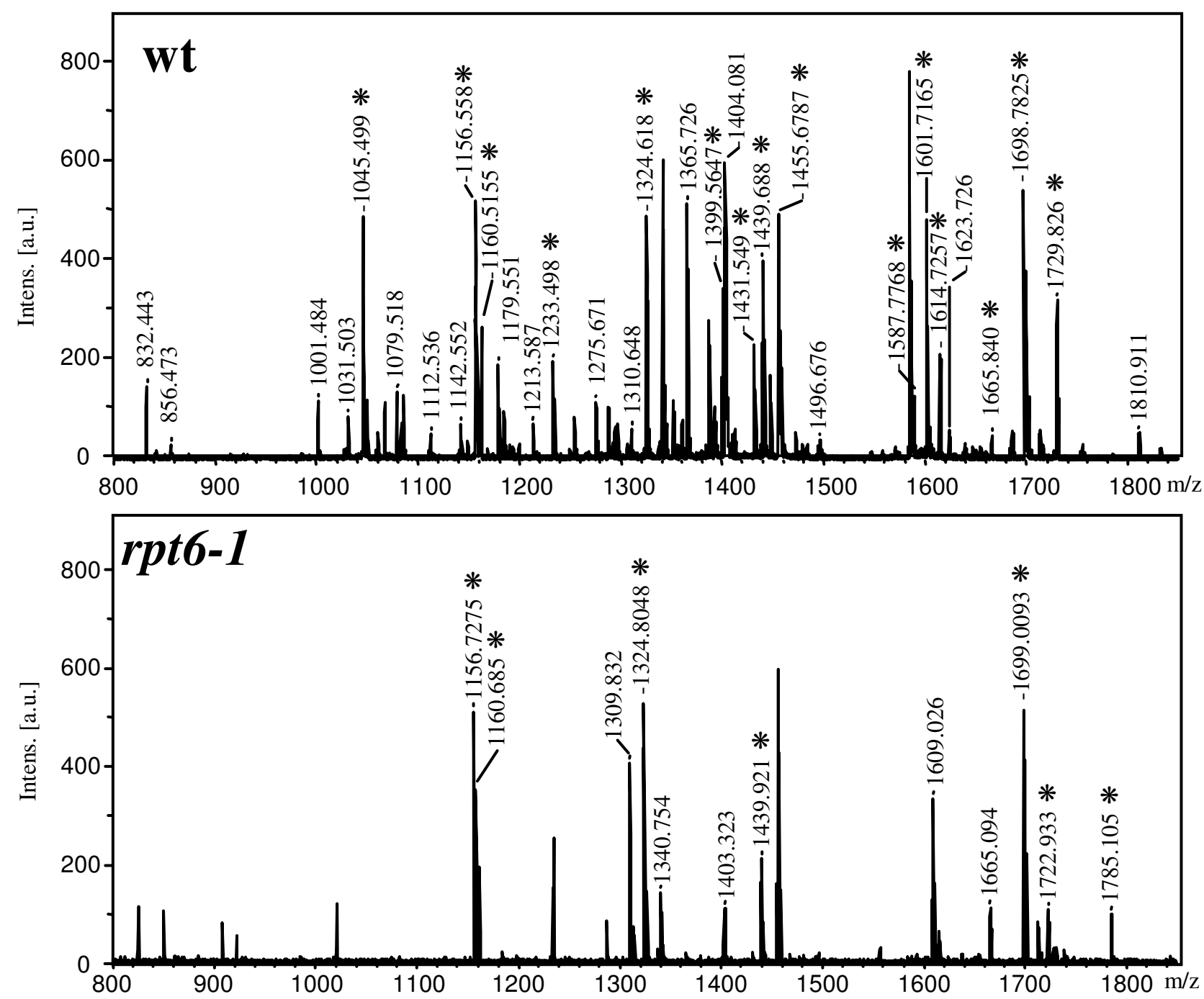

Figure 6

Representative MS spectra of $\alpha$ l-subunits. The trypsin-digested peptide mixture was extracted from gel pieces and analyzed by MALDI-TOF-MS. Peaks that matched in the $w>$ database search indicated with asterisks. Panels correspond to a spot from the $20 S_{w}$ (wt) and $20 S_{r}$ (rpt6-I) proteasomes, respectively.

1 , the $\alpha 1$-subunit shifted slightly and the $\alpha 7$-subunit shifted markedly towards the acidic side of the gel, while both migrated slowly in SDS-PAGE (Figs. 5 and 4B) indicating that the weak activities of the $20 \mathrm{~S}_{\mathrm{r}}$ proteasome are a consequence of changes in these two $\alpha$-subunits. At least two explanations can be offered to account for the lower activity of the $20 \mathrm{~S}$ proteasome in the $r p t 6-1$ mutant. One, the rpt6-1 mutation caused changes in the $\alpha$-subunits of the $20 \mathrm{~S}$ proteasome by interfering with assembly of the 26 S proteasome. Two, stress caused by the rpt6-1 muta- tion induced subsequent compensatory changes in the subunits.

Groll et al. [31] demonstrated that the channel of the 20S proteasome is too narrow for substrate entry, but that the proteasome may become active when the channel is open. As shown in their study, activity of the 20S proteasome is controlled by the $\alpha$-channel. Here, we identified two high molecular weight forms of the $\alpha$-subunits in rpt6-1 that resulted in weak $20 \mathrm{Sr}$ proteasome activity. We speculate 

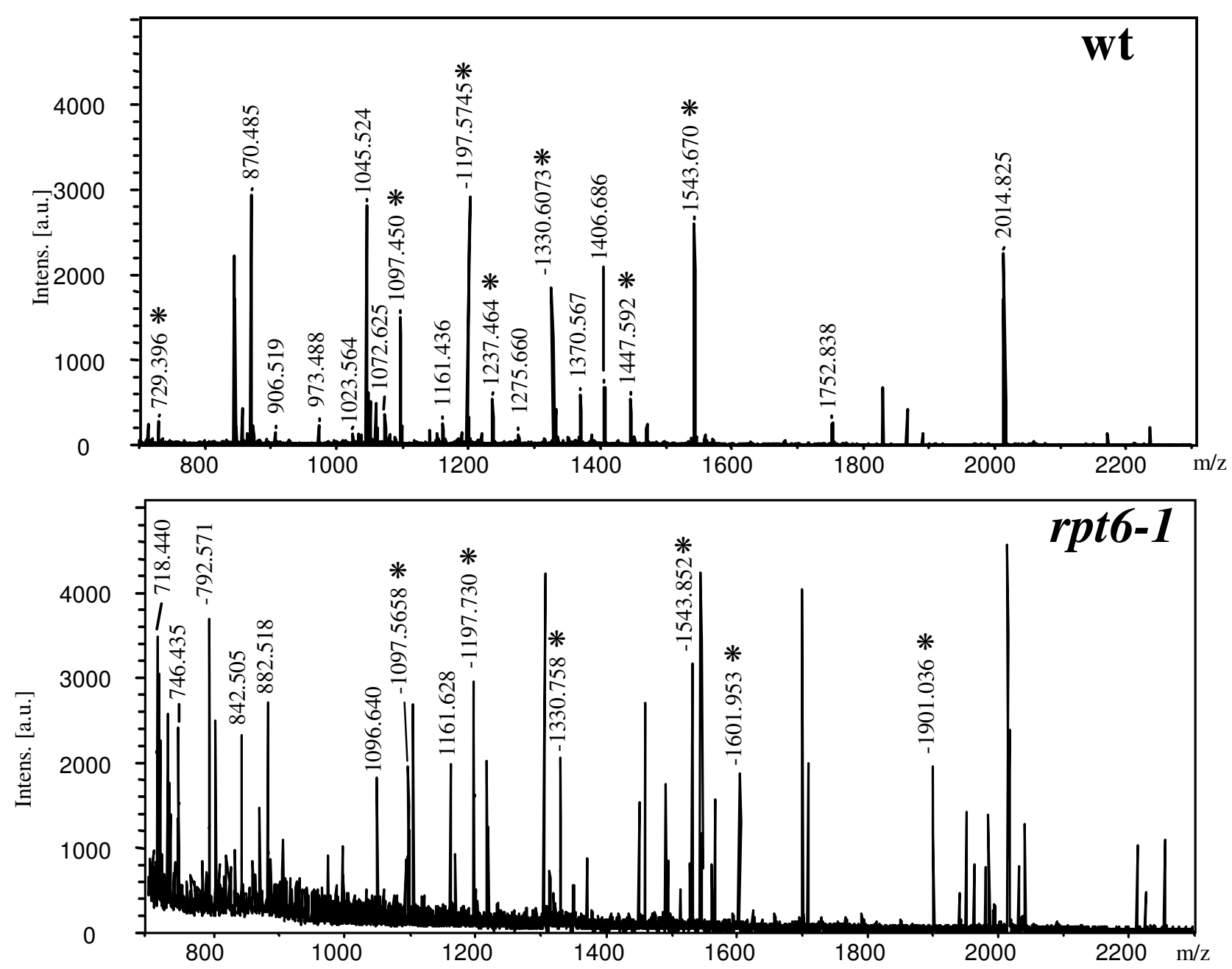

Figure 7

Representative MS spectra of $\alpha$-subunits. The trypsin-digested peptide mixture was extracted from gel pieces and analyzed by MALDI-TOF-MS. Peaks that matched in the $w>$ database search are indicated with asterisks. Panels correspond to a spot from $20 \mathrm{~S}_{\mathrm{w}}(\mathrm{wt})$ and $20 \mathrm{~S}_{\mathrm{r}}($ rpt6-I) proteasomes, respectively.

Table 2: Chymotrypsin-like activity of the $20 \mathrm{~S}$ proteasome in the rpt6-I mutant as a function of temperature shift ${ }^{a}$.

\begin{tabular}{|c|c|c|c|c|c|c|}
\hline \multirow[t]{3}{*}{ Incubation temp. } & \multicolumn{2}{|c|}{ Chymotrypsin-like activity (nmol/mg/min) } & \multirow[t]{2}{*}{ wt/rpt6-I } & \multicolumn{2}{|c|}{ Chymotrypsin-like activity (nmol/mg/min) } & \multirow[t]{2}{*}{$w t / r p t 6-I$} \\
\hline & & & & & & \\
\hline & wt & rpt6-l & & wt & rpt6-I & \\
\hline $25^{\circ} \mathrm{C}$ & $0.58 \pm 0.02$ & $0.07 \pm 0.03$ & 8.0 & $4.42 \pm 0.29$ & $2.63 \pm 0.31$ & 1.6 \\
\hline $37^{\circ} \mathrm{C}$ & $0.42 \pm 0.04$ & $0.51 \pm 0.04$ & 0.8 & $3.33 \pm 0.70$ & $3.73 \pm 0.22$ & 0.8 \\
\hline
\end{tabular}

${ }^{a}$ Exponentially-growing cells at $25^{\circ} \mathrm{C}$ were shifted to $37^{\circ} \mathrm{C}$ and incubated for $8 \mathrm{~h}$. Activity assays were carried out with the active Q-sepharose fractions from both strains containing equal amounts of proteasome as described in the methods using Suc-LLVY-MCA as a substrate in the presence $(0.01 \%)$ and absence of SDS. The values are means \pm SD of three independent experiments. 
A
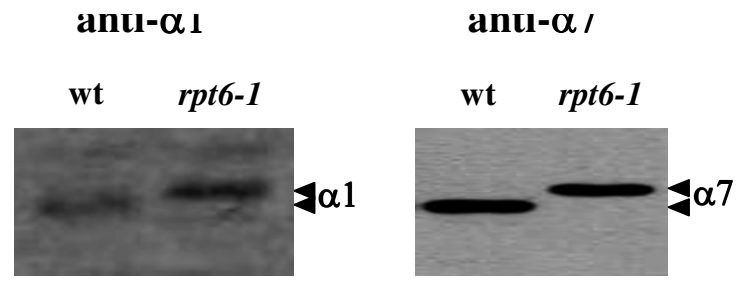

B

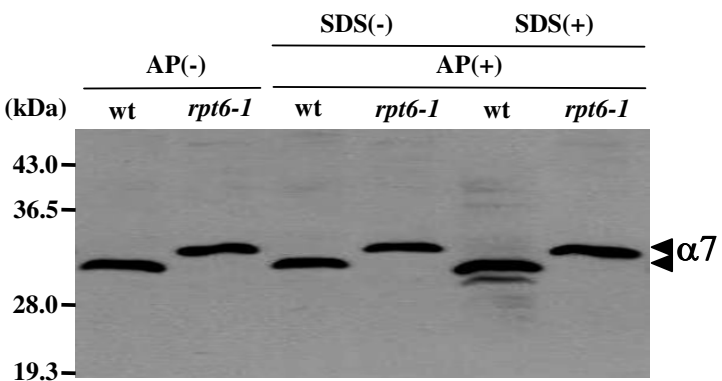

\section{Figure 8}

Identification of $\alpha \mathrm{I}$ - and $\alpha$ 7-subunits by western blot analysis. (A) The $20 \mathrm{~S}$ proteasomes were subjected to SDSPAGE in a $12 \%$ polyacrylamide gel and electrophoretically transferred to a PVDF membrane. The $\alpha \mathrm{I}$ - and $\alpha 7$-subunits were detected using their respective antibodies as described in the methods. (B) Cells from wild-type and the rpt6-I mutant (wt, rpt6-l) grown at $25^{\circ} \mathrm{C}\left(\mathrm{OD}_{600 \mathrm{~nm}}=1.0\right)$ were harvested and the cell extracts were applied to a Q-sepharose column. Active $\mathrm{Q}$-sepharose fractions were concentrated and treated with (AP+) or without (AP-) alkaline phosphatase as described in the methods. The samples were then subjected to SDS-PAGE in a 12\% polyacrylamide gel. The $\alpha 7$-subunit was detected by immunostaining with anti$\alpha 7$ antibody [26,27].

that the $\alpha$-subunit(s) are differentially modified in the 20Sr proteasome and block the gated channel that allows restricted entry of substrate into the proteasome catalytic cavity since the substrate specific activities in the absence of SDS were low, but optimal activities in the presence of SDS were found to converge with those of the 20Sw proteasome (Fig. 1).

To reconfirm the results described above, we characterized the differentially migrated subunits in the $20 \mathrm{~S}_{\mathrm{r}}$ proteasome by Western blotting. The results reconfirmed the slow migration of $\alpha 1$ and $\alpha 7$ in the 20S proteasome compared to those of the $20 \mathrm{~S}_{\mathrm{w}}$ proteasome (Fig. 8A). Phosphorylation of the proteasome has been reported to modulate a number of functions including catalytic activity [37]. Iwafune et al. $[26,38]$ demonstrated that the $\alpha 7$ subunit in yeast is a major phosphorylatable subunit. Regulation of the proteasome complex by phosphorylation of the $\alpha 7$-subunit in COS-7 cells has been demonstrated by Rivett and colleagues $[39,40]$. Tokumoto et al. [27] detected a high molecular weight phosphorylated $\alpha 4$-subunit in the 26S proteasome from immature Xenopus oocyte. These findings led us to test whether the differentially migrating $\alpha$-subunits in $r p t 6-1$ were phosphorylated. No significant change in mobility or intensity was detected for $\alpha 7$ treated with alkaline phosphatase (Fig. $8 \mathrm{~B}$ ) or for the similarly treated $\alpha 1$-subunit (data not shown).

The rpt6-1 mutant arrests cell division within one cycle at the restrictive temperature [13] and under normal growth conditions, we found changes in the $\alpha 1$ - and $\alpha 7$-subunits of the 20S proteasome in the rpt6-1 mutant. One question that remains to be clarified is whether the observed changes are affected at the restrictive temperature. The data presented in figure 9 indicate that the change in $\alpha 7$ in the rpt6-1 mutant grown at $25^{\circ} \mathrm{C}$ disappeared during the response to cell stress. Interestingly, in parallel with the disappearance, normalization of LLVY-hydrolyzing activity was observed in the absence of SDS (Table 2). One likely explanation of the data presented here is that the $\alpha 1$ - and $\alpha 7$-subunits exist in the $20 \mathrm{~S}_{\mathrm{r}}$ proteasome in an immature form that result in a gating defect in the proteasome channel. A qualitative change to these subunits occurred at $37^{\circ} \mathrm{C}$ to cause them to mature because under stressful conditions, the cell is in greatest need of optimal proteasome function. Alternatively, newly synthesized proteasomes in the rpt6-1 mutant may be refractory to modification due to excessive stress at the restrictive temperature.

Although the purified proteasomes from both strains produced single bands in nondenaturing-PAGE (Fig. 4A), they differed in composition in 2-DE (Fig. 5). One possibility is that the compositional differences reflect differences in co-purified proteasome-interacting proteins (PIPs). Five proteins (p1, p2, p3, p4, p5) found with the $20 \mathrm{~S}$ proteasome were also identified by database searching (Table 1). The protein, $\mathrm{p} 1$ was found in the wild-type strain but not in the rpt6-1 mutant. Therefore, we cannot rule out the possibility that the PIP, p1, plays a supplementary role in normal $20 \mathrm{~S}$ proteasome function in yeast.

To show that the changes found in the $20 \mathrm{~S}_{\mathrm{r}}$ proteasome were dependent on the rpt6-1 mutation, the rpt6-1 strain was transformed with the wild-type allele as described in methods. The RPT6 allele was found to complement the temperature sensitivity of the mutant. The $20 \mathrm{~S}$ proteasome purified from the transformant was analyzed to examine whether changes in the $\alpha$-subunits and the weak peptidase activities were eliminated. Interestingly, the banding pattern of the 20S proteasome subunits of the transformant was found to be similar to that of wild-type 


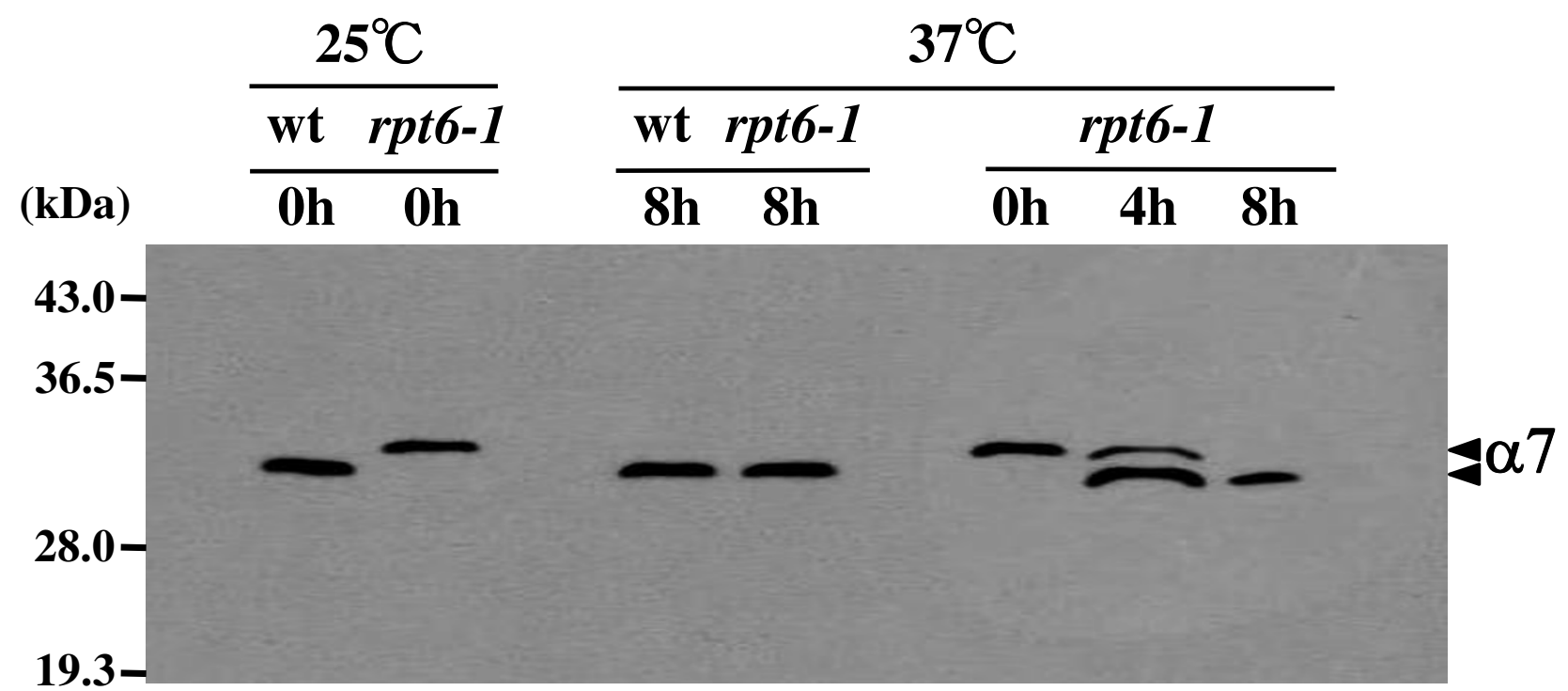

\section{Figure 9}

Molecular weight level of the $\alpha 7$-subunit in the rpt6-I mutant under permissive and restrictive conditions. Cells from wild-type and the rpt6-l mutant (wt, rpt6-l) were grown at $25^{\circ} \mathrm{C}$ to exponential phase at $\mathrm{OD}_{600 \mathrm{~nm}}=2.0(0 \mathrm{~h})$. The cultures were then immediately shifted to $37^{\circ} \mathrm{C}$ and incubated for several hours as indicated. Cell extracts were applied to a $\mathrm{Q}-$ sepharose column. The molecular weight level of the $\alpha 7$-subunits in both strains produced during the indicated incubation period was assayed by Western blotting using anti- $\alpha 7$ antibody.

by SDS-PAGE analysis using a $12 \%$ polyacrylamide gel. Further, the slow mobility of the $\alpha$-subunits and the weak peptidase activities were rescued in the transformant as well (data not shown).

\section{Conclusion}

The 20S proteasome purified from the rpt6-1 mutant exhibited low levels of peptidase activities compared to the wild-type strain. The activator-mediated activation profile of the $20 \mathrm{~S}$ proteasome from $r p t 6-1$ also differed from that observed in the wild-type $20 \mathrm{~S}$ proteasome. The $\alpha 1$ - and $\alpha 7$-subunits of the 20S proteasome in the rpt6-1 mutant were found to differ from their wild-type counterparts.

\section{Abbreviations}

SDS: Sodium dodecylsulfate; TFA: Trifluoroacetic acid; $\mathrm{pI}$ : Isoelectric point; PGPH: Post-glutamylpeptide hydrolysis; IPG: Immobilized pH gradient; PMF: Peptide mass fingerprint

\section{Authors' contributions}

AC carried out the biochemical and molecular experiments, the peptide mass fingerprinting, and drafted the manuscript. TT participated in design and coordination of experiments and helped to draft the manuscript. HD helped to perform the peptide mass fingerprinting. TU helped to construct plasmids. SY assisted with the design and coordination of the study. All authors read and approved the final manuscript.

\section{Acknowledgements}

This work was supported by Grants-in-Aid from Suzuki Motor Corporation, Hamamatsu City; Shizuoka Research Institute, Shizuoka City; and for Scientific Research on priority areas from the Ministry of Education, Culture, Sports, Science and Technology of Japan. This study was partially carried out using equipment of the Institute for Genetic Research and Biotechnology, National University Corporation, Shizuoka University.

\section{References}

I. Bochtler M, Ditzel L, Groll M, Hartmann C, Huber R: The proteasome. Annu Rev Biophys Biomol Struct 1999, 28:295-3I7.

2. Hershko $A$, Ciechanover $A$ : The ubiquitin system for protein degradation. Annu Rev Biochem 1992, 61:761-807.

3. Glickman MH, Rubin DM, Fried VA, Finley D: The regulatory particle of the S. cerevisiae proteasome. Mol Cell Biol 1998, 18:3|49-3162.

4. DeMot R, Nagy I, Walz J, Baumeister W: Proteasomes and other self-compartmentalizing proteases in prokaryotes. Trends Microbiol 1999, 7:88-92.

5. Larsen CN, Finley D: Protein translocation channels in the proteasome and other proteases. Cell 1997, 91:43I-434.

6. Braun BC, Glickman M, Kraft R, Dahlmann B, Kloetzel PM, Finley D, Schmidt M: The base of the proteasome regulatory particle exhibits chaperone-like activity. Nat Cell Biol 1999, I:22I-226.

7. Groll M, Ditzel L, Lowe J, Stock D, Bochtler M, Bartunik HD, Huber $R$ : Structure of $20 \mathrm{~S}$ proteasome from yeast at $2.4 \AA$ resolution. Nature 1997, 386:463-47I.

8. Orlowski M: The multicatalytic proteinase complex, a major extralysosomal proteolytic system. Biochemistry 1990, 29: $10289-10297$

9. Bajorek M, Glickman MH: Keepers at the final gates: regulatory complexes and gating of the proteasome channel. Cell Mol Life Sci 2004, 6I: 1579-I588. 
10. Rubin DM, Glickman MH, Larsen CN, Dhruvakumar S, Finley D: Active site mutants in the six regulatory particle ATPases reveal multiple roles for ATP in the proteasome. EMBO J 1998, I 7:4909-49|9.

II. Kohler A, Cascio P, Leggett DS, Woo KM, Goldberg AL, Finley D: The axial channel of the proteasome core particle is gated by the Rpt2 ATPase and controls both substrate entry and product release. Mol Cell 200I, 7:II43-III52.

12. Coux O, Tanaka K, Goldberg AL: Structure and functions of the 20S and 26S proteasomes. Annu Rev Biochem 1996, 65:80I-847.

13. Ghislain M, Udvardy A, Mann C: S. cerevisiae 265 protease mutants arrest cell division in $\mathbf{G} 2 /$ metaphase. Nature 1993 , 366:358-36I.

14. Wang Y, Marotti LA, Lee MJ, Dohlman HG: Differential regulation of $\mathbf{G}$ protein $\alpha$ subunit trafficking by mono- and polyubiquitination. J Biol Chem 2005, 280:284-29l.

15. Piwko W, Jentsch S: Proteasome-mediated protein processing by bidirectional degradation initiated from an internal site. Nat Struct Mol Biol 2006, I 3(8):69|-697.

16. Collins KA, Furuyama S, Biggins S: Proteolysis contributes to the exclusive centromere localization of the yeast Cse4/CENP A histone H3 variant. Curr Biol 2004, 14:1968-1972.

17. Schork SM, Thumm M, Wolf DH: Catabolite inactivation of fructose-I, 6-bisphosphatase of Saccharomyces cerevisiae. J Biol Chem 1995, 270:26446-26450.

18. Mumberg D, Müller R, Funk M: Yeast vectors for the controlled expression of heterologous proteins in different genetic backgrounds. Gene 1995, 156:1 19-122.

19. Bradford MM: A rapid and sensitive method for the quantitation of microgram quantities of protein utilizing the principle of protein-dye binding. Anal Biochem 1976, 72:248-254.

20. Yamada S, Hojo K, Yoshimura H, Ishikawa K: Reaction of $20 \mathrm{~S}$ proteasome: Shift of SDS-dependent activation profile by divalent cations. J Biochem 1995, II7:1 162-II69.

21. Laemmli UK: Cleavage of structural proteins during the assembly of the head of bacteriophage T4. Nature 1970 227:680-685

22. Wakata $Y$, Tokumoto $M$, Horiguchi R, Ishikawa $K$, Nagahama $Y$, Tokumoto T: Identification of $\alpha$-type subunits of the Xenopus $20 S$ proteasome and analysis of their changes during the meiotic cell cycle. BMC Biochem 2004, 5:18.

23. Ludemann R, Lerea KM, Etlinger JD: Copurification of casein kinase II with $20 \mathrm{~S}$ proteasomes and phosphorylation of a $\mathbf{3 0}$. kDa proteasome subunit. J Biol Chem 1993, 268:174|3-17417.

24. Horiguchi $\mathrm{R}$, Dohra $\mathrm{H}$, Tokumoto $\mathrm{T}$ : Comparative proteome analysis of changes in the $26 \mathrm{~S}$ proteasome during oocyte maturation in goldfish. Proteomics 2006, 6:4195-4202.

25. Castro-Borges W, Cartwright J, Ashton P, Braschi S, Guerra R, Rodrigues V, Wilson RA, Curwen RS: The 20 S proteasome of Schistosoma mansoni: A proteomic analysis. Proteomics 2007, 7:1065-1075.

26. Iwafune $\mathrm{Y}$, Kawasaki $\mathrm{H}$, Hirano $\mathrm{H}$ : Electrophoretic analysis of phosphorylation of the yeast $20 \mathrm{~S}$ proteasome. Electrophoresis 2002, 23:329-338

27. Tokumoto M, Horiguchi R, Nagahama $Y$, Tokumoto T: Identification of the Xenopus $20 \mathrm{~S}$ proteasome $\alpha 4$ subunit which is modified in the meiotic cell cycle. Gene 1999, 239:30I-308

28. McGuire MJ, McCullough ML, Croall DE, DeMartino GN: The high molecular weight multicatalytic proteinase, macropain, exists in a latent form in human erythrocytes. Biochim Biophys Acta 1989, 995:181-186.

29. Arribas ], Castano J: Kinetic studies of the differential effect of detergents on the peptidase activities of the multicatalytic proteinase from rat liver. I Biol Chem 1990, 265: I3969-I3973.

30. Lowe J, Stock D, Jap B, Zwickl P, Baumeister W, Huber R: Crystal structure of the $20 \mathrm{~S}$ proteasome from the archaeon $\mathrm{T}$. acidophilum at 3.4 A resolution. Science 1995, 268:533-539.

31. Groll M, Bajorek M, Kohler A, Moroder L, Rubin DM, Huber R, Glickman $\mathrm{MH}$, Finley $\mathrm{D}$ : A gated channel into the proteasome core particle. Nat Struct Biol 2000, 7:1062-1067.

32. Chen $P$, Hochstrasser $M$ : Biogenesis, structure and function of the yeast 20 S proteasome. EMBO J I995, I4:2620-2630.

33. Thomas AR, Oosthuizen V, Naude RJ: Differential effects of detergents, fatty acids, cations and heating on ostrich skeletal muscle 20S proteasome. Comp Biochem Physiol B 2005, | 40:343-348.
34. Dahlmann B, Rutschmann M, Kuehn L, Reinauer H: Activation of the multicatalytic proteinase from rat skeletal muscle by fatty acids or sodium dodecyl sulphate. Biochem J 1985, 228:17|-177.

35. Yanagawa Y, Ohhshi A, Murakami Y, Saeki Y, Yokosawa H, Tanaka K, Hashimoto J, Sato T, Nakagawa H: Purification and characterization of the 26S proteasome from cultured rice (Oryza sativa) cells. Plant Sci 1999, | 49:33-4I.

36. Hoffman L, Pratt G, Rechsteiner M: Multiple forms of the 20S multicatalytic and the $26 \mathrm{~S}$ ubiquitin/ATP-dependent proteases from rabbit reticulocyte lysate. I Biol Chem 1992, 267:22362-22368.

37. Horiguchi R, Tokumoto T: Modifications to proteasomal subunits during meiotic cell cycle-implications in the regulation of fertilization through proteasome activity. In New Impact on Protein Modifications in the Regulation of Reproductive System Edited by: Tokumoto T. Kerala India: Research Signpost; 2005:37-60.

38. Iwafune $\mathrm{Y}$, Kawasaki $\mathrm{H}$, Hirano $\mathrm{H}$ : Identification of three phosphorylation sites in the $\alpha 7$ subunit of the yeast 20S proteasome in vivo using mass spectrometry. Arch Biochem Biophys 2004, 43 I:9-15.

39. Rivett AJ, Bose S, Brooks P, Broadfoot KI: Regulation of proteasome complexes by gamma-interferon and phosphorylation. Biochimie 200I, 83:363-366.

40. Bose S, Stratford FL, Broadfoot KI, Mason GG, Rivet AJ: Phosphorylation of $20 \mathrm{~S}$ proteasome alpha subunit C8 (alpha7) stabilizes the $26 \mathrm{~S}$ proteasome and plays a role in the regulation of proteasome complexes by gamma-interferon. Biochem 2004, 378: $177-184$
Publish with Bio Med Central and every scientist can read your work free of charge

"BioMed Central will be the most significant development for disseminating the results of biomedical research in our lifetime. "

Sir Paul Nurse, Cancer Research UK

Your research papers will be:

- available free of charge to the entire biomedical community

- peer reviewed and published immediately upon acceptance

- cited in PubMed and archived on PubMed Central

- yours - you keep the copyright

Submit your manuscript here:

http://www.biomedcentral.com/info/publishing_adv.asp
BioMedcentral 